\title{
DISPONIBILIDADE DE NITRATO EM SOLOS BRASILEIROS SOB EFEITO DA CALAGEM E DE FONTES E DOSES DE NITROGÊNIO'1
}

\author{
CARLOS ALBERTO SILVA ${ }^{2}$ e FABIANO RIBEIRO DO VALE
}

\begin{abstract}
RESUMO - Este trabalho objetivou avaliar os efeitos da calagem e de fontes e doses de $\mathrm{N}$ sobre a disponibilidade de nitrato, em amostras $(0-20 \mathrm{~cm})$ de solos brasileiros. Foram conduzidos dois experimentos: um com cinco solos da Bahia e o outro com cinco solos de Minas Gerais. Os materiais de solo foram previamente umedecidos e incubados por sete dias, a $26^{\circ} \mathrm{C}$, visando ativar a flora microbiana. Nas amostras de solo da Bahia, aplicou-se a uréia ou o sulfato de amônio nas concentrações de 50, 100, 150 e $200 \mathrm{mg}$ de $\mathrm{N}$ por kg de solo e nas de Minas Gerais, foi avaliado o efeito da calagem sobre a nitrificação. Os materiais de solo foram incubados a $26^{\circ} \mathrm{C}$ por 15 dias. Independentemente da dose de $\mathrm{N}$ aplicada, a uréia nitrificou mais rapidamente do que o sulfato de amônio. Na Areia Quartzosa não foi observada nitrificação líquida do $\mathrm{N}$-sulfato de amônio, sendo constatada, porém, a oxidação do N-uréia. A calagem afetou a nitrificação, notando-se nos solos que receberam calcário maior disponibilidade de nitrato. A saturação por bases e o teor de matéria orgânica apresentaram, respectivamente, a melhor correlação com o nitrato formado e os teores de uréia presentes no solo ao término da incubação.
\end{abstract}

Termos para indexação: matéria orgânica, $\mathrm{pH}$ do solo, urease, sulfato de amônio, nitrificação.

\section{NITRATE AVAILABILITY IN BRAZILIAN SOILS UNDER EFFECT OF LIMING AND SOURCES AND AMOUNTS OF NITROGEN}

\begin{abstract}
The aim of this work was to evaluate the effect of liming and sources and doses of nitrogen on nitrate availability in Brazilian soils. Two experiments were carried out: one with five soils from Bahia State and the other with five soils from Minas Gerais State. Soil samples were previously moistened and incubated at $26^{\circ} \mathrm{C}$ in order to activate the microorganism population. Soil samples from Bahia State were incubated with 50, 100, 150 e $200 \mathrm{mg}$ of $\mathrm{N}$ per kg of soil as ammonium sulfate or urea and in the Minas Gerais soils it was evaluated the effect of liming on nitrification. Soil samples were incubated at $26^{\circ} \mathrm{C}$ during 15 days. Urea nitrified faster than ammonium sulfate. The sandy soil did not exhibit net nitrification following ammonium application, but nitrification in this soil was significantly higher under urea. The nitrate availability increases with the liming of Minas Gerais soils. Nitrification rate showed to be highly correlated with base saturation whereas urea hydrolysis was correlated with organic matter content.
\end{abstract}

Index terms: organic matter, soil $\mathrm{pH}$, urease, ammonium sulfate, nitrification.

\section{INTRODUÇÃO}

No Brasil, a uréia e o sulfato de amônio constituem as principais fontes de N. A uréia, representando

\footnotetext{
${ }^{1}$ Aceito para publicação em 27 de janeiro de 2000.

${ }^{2}$ Eng. Agrôn., Dr., Embrapa-Centro Nacional de Pesquisa de Solos, Rua Jardim Botânico, 1024, Jardim Botânico, CEP 22460-000 Rio de Janeiro, RJ.

E-mail: csilva@cnps.embrapa.br

${ }^{3}$ Eng. Agrôn., Ph.D., Dep. de Ciência do Solo, Universidade Federal de Lavras (UFLA), Caixa Postal 37, CEP 37200-000 Lavras, MG. E-mail: fabiano@ufla.br
}

cerca de 50\% do mercado, quando aplicada ao solo, sofre, inicialmente, hidrólise, produzindo amônia e gás carbônico, numa reação mediada pela urease. Essa reação inicial da uréia apresenta importantes aspectos, entre os quais a elevação do $\mathrm{pH}$ do solo, para a faixa de 8 a 9 , nas imediações do grânulo desse fertilizante. Por sua vez, o sulfato de amônio, que representa cerca de $25 \%$ do mercado, quando aplicado ao solo, por dissolução, produz diretamente íons amônio. Uma vez presente no solo, o amônio pode ser oxidado a nitrato, numa reação mediada por bactérias autotróficas e denominada nitrificação. 
A intensidade da nitrificação, que, em última instância, determina a disponibilidade de nitrato no sistema solo-planta, varia tanto com o grau de fertilidade do solo quanto com a molécula carreadora de $\mathrm{N}$ (Alexander, 1965; Haynes, 1986). As maiores taxas de nitrificação têm sido obtidas nos solos onde se procede a correção da acidez do solo (Haynes, 1986; Hayatsu \& Kosuge, 1993; Kreutzer, 1995). Em latossolos do sul de Minas Gerais, Silva et al. (1994) verificaram que a calagem promoveu aumento na disponibilidade de nitrato, sendo os maiores teores de $\mathrm{N}$-nítrico observados em condições de $\mathrm{pH}$ próximo da neutralidade ou nos tratamentos onde se procedeu a eliminação do $\mathrm{Al}$ tóxico e o aumento nos teores de Ca no solo. A disponibilidade de amônio para os microrganismos nitrificadores e o efeito de fertilizantes sobre o $\mathrm{pH}$ do solo e sobre a população de nitrificadores são os principais fatores que governam a variação nas velocidades de transformação do N suprido pelos adubos nitrogenados (Arora et al., 1986).

Avaliando a taxa de nitrificação do $\mathrm{N}$ proveniente da uréia e sulfato de amônio, Melo et al. (1980) não verificaram diferenças acentuadas entre a nitrificação desses dois fertilizantes. Entretanto, Arora et al. (1986) observaram que o amônio da uréia nitrificou mais rapidamente do que aquele oriundo do sulfato de amônio, na ausência de carbonato de cálcio. Em solo ácido sob vegetação de cerrado, Hayatsu \& Kosuge (1993) verificaram que o suprimento de $\mathrm{N}$ na forma de uréia e a calagem causaram aumento na população de bactérias autotróficas nitrificadoras, o que resultou em incremento na taxa de nitrificação. Segundo Melo (1987), a taxa de nitrificação em solos ácidos é reduzida, mas, no caso específico da uréia, ela poderá ser alta, pela elevação do $\mathrm{pH}$ em consequiência da hidrólise desse fertilizante.

Outro fator limitante à nitrificação é a concentração de amônio no solo. Normalmente, os valores de $\mathrm{Km}$, que indicam a concentração de substrato para se atingir metade da velocidade máxima de nitrificação, variam de 1 a $10 \mathrm{mg}$ de $\mathrm{N}-\mathrm{NH}_{4}{ }^{+}$por $\mathrm{L}$ de solução de solo. Essas concentrações são encontradas em áreas sob fertilização intensiva de N, de modo que, na maioria dos solos, a nitrificação é aumentada em áreas com aplicações de até $300 \mathrm{mg}$ de $\mathrm{N}$ por $\mathrm{kg}$ de solo (Malhi \& McGill, 1982; Haynes, 1986).
Assim, face à possibilidade de a uréia e do sulfato de amônio condicionarem de forma diferenciada a intensidade da nitrificação, assume importância o fato de as plantas poderem ser expostas a diferentes quantidades e proporções de nitrato e amônio. Diante dessa possibilidade, há implicações tanto do ponto de vista agronômico quanto do ecológico, pois o balanço dessas formas nitrogenadas afeta o crescimento das plantas (Vale et al., 1998), e a maior presença de nitrato no solo pode representar, em áreas com uso mais intensivo de $\mathrm{N}$, maiores perdas de $\mathrm{N}$ do sistema solo-planta e risco de poluição de mananciais de água.

O presente estudo objetivou avaliar a disponibilidade de nitrato em função da aplicação de doses crescentes de uréia ou de sulfato de amônio, em amostras de solos brasileiros sob efeito ou não da calagem.

\section{MATERIAL E MÉTODOS}

Foram conduzidos dois experimentos no laboratório de Relação Solo-Planta do Departamento de Ciência do Solo da Universidade Federal de Lavras, no período de julho a outubro de 1992.

No primeiro experimento foram utilizadas cinco amostras de solo $(0-20 \mathrm{~cm})$ do sudoeste da Bahia: Latossolo Vermelho-Amarelo álico (LV1), Latossolo Vermelho-Amarelo eutrófico (LV2), Latossolo Amarelo álico (LA), Podzólico Vermelho-Amarelo eutrófico (PV) e Areia Quartzosa distrófica (AQ).

Os materiais de solo foram secados ao ar, peneirados (2 mm) e caracterizados quimicamente, conforme Embrapa (1979), à exceção da matéria orgânica (Raij \& Quaggio, 1983), e fisicamente (textura), segundo Camargo et al. (1986) (Tabela 1).

Adotou-se o delineamento experimental inteiramente casualizado, com os tratamentos distribuídos num arranjo fatorial $5 \times 2 \times 4$ ( 5 solos; 2 fontes de $\mathrm{N}$ e 4 doses de $\mathrm{N}$ ). A fim de avaliar o nitrato produzido, foram utilizadas duas fontes de N, uréia e sulfato de amônio, nas concentrações de 50, 100, 150 e $200 \mathrm{mg}$ de N por kg de solo. Para cada concentração, em três repetições, tomaram-se $50 \mathrm{~g}$ de solo, acondicionadas em tubos de vidro de $100 \mathrm{~mL}$, e adicionaram-se $20 \mathrm{~mL}$ de água. Em seguida, procedeu-se à incubação por sete dias, a $26^{\circ} \mathrm{C}$, para ativar a flora microbiana. Após esse período, adicionou-se uréia ou sulfato de amônio, nas cinco concentrações, e procedeu-se à incubação $\left(26^{\circ} \mathrm{C}\right)$ dos solos por 15 dias, com umidade mantida constante a -0,006 MPa para AQ e LV1, e a -0,01 MPa para os demais solos. 
TABELA 1. Caracterização química e textural de amostras da camada superficial $(0-20 \mathrm{~cm})$ de cinco solos do sudoeste da Bahia.

\begin{tabular}{|c|c|c|c|c|c|c|c|c|c|c|c|}
\hline Solo $^{1}$ & $\mathrm{pH}$ & $\begin{array}{c}\mathrm{K} \\
---(\mathrm{mg} \mathrm{dm} \\
-3\end{array}$ & ${ }_{3}^{P}$ & $\mathrm{Ca}$ & $\begin{array}{l}\mathrm{Mg} \\
-(\mathrm{cm}\end{array}$ & $\begin{array}{r}\mathrm{Al} \\
\left.\mathrm{dm}^{-3}\right)\end{array}$ & $\mathrm{H}+\mathrm{Al}$ & MO & $\begin{array}{l}\text { Areia } \\
--(g\end{array}$ & Silte & Argila \\
\hline LV1 & 6,6 & 42 & 74 & 2,5 & 0,6 & 0,1 & 1,3 & 16,0 & 780 & 20 & 200 \\
\hline LV2 & 5,8 & 117 & 21 & 4,9 & 0,1 & 0,1 & 2,6 & 21,0 & 620 & 140 & 240 \\
\hline LA & 6,8 & 172 & 31 & 5,0 & 0,6 & 0,1 & 1,3 & 19,0 & 620 & 220 & 160 \\
\hline PV & 6,3 & 98 & 17 & 4,3 & 0,7 & 0,1 & 1,9 & 23,0 & 690 & 140 & 170 \\
\hline AQ & 5,2 & 14 & 18 & 0,8 & 0,6 & 0,1 & 2,1 & 7,0 & 950 & 10 & 40 \\
\hline
\end{tabular}

${ }^{1}$ LV1: Latossolo Vermelho-Amarelo; LV2: Latossolo Vermelho-Amarelo; LA: Latossolo Amarelo; PV: Podzólico Vermelho-Amarelo; AQ: Areia Quartzosa.

Após o período de incubação, procedeu-se à determinação do pH em água (solo:água - 1:2,5) e dos teores de amônio e nitrato, que foram extraídos com $\mathrm{KCl} 1 \mathrm{~N}$ e determinados por destilação, segundo Keeney \& Nelson (1982). A uréia remanescente no solo foi quantificada, seguindose marcha analítica proposta por Bremner (1982).

No segundo experimento, foram utilizadas amostras superficiais $(0-20 \mathrm{~cm})$ de cinco solos representativos do sul de Minas Gerais: Latossolo Roxo (LR; vegetação original - floresta tropical subcaducifólia), Latossolo Vermelho-Escuro (LE; vegetação original - cerrado tropical subcaducifólio), Latossolo Vermelho-Amarelo (LV3; vegetação original - cerrado tropical subcaducifólio), Latossolo Vermelho-Amarelo (LV4; vegetação original cerrado tropical subcaducifólio), Glei Pouco Húmico (GPH; vegetação original - campo tropical hidrófilo). A caracterização química dos solos, após a aplicação dos tratamentos, é apresentada na Tabela 1. Determinaram-se $\mathrm{K}$ e $\mathrm{P}$ em Mehlich-1, pH em água e em cloreto de cálcio, e $\mathrm{Ca}, \mathrm{Mg}, \mathrm{Al}$ e H+Al, conforme Embrapa (1979). O N total foi quantificado de acordo com Bremner \& Mulvaney (1982). O amônio e o nitrato presentes nos solos foram determinados seguindo-se metodologia proposta por Keeney \& Nelson (1982). A análise granulométrica das amostras de solo foi efetuada conforme Camargo et al. (1986).

$\mathrm{O}$ delineamento experimental utilizado foi o inteiramente casualizado, com três repetições, em esquema fatorial, determinando 30 tratamentos, obtidos pela combinação de cinco solos (LR, LE, LV3, LV4 e GPH), duas fontes de $\mathrm{N}$ (uréia e sulfato de amônio) e três níveis de acidez do solo.

As amostras dos solos foram incubadas por 30 dias com $\mathrm{CaCO}_{3}$ e $\mathrm{MgCO}_{3}$ p.a., mediante utilização de três níveis de saturação por bases (Tabela 2). Para o cálculo da necessidade de calcário, utilizou-se a fórmula proposta por Raij (1991). Após essa etapa, as amostras foram pe- neiradas e secadas, coletando-se $50 \mathrm{~g}$ de cada solo, para cada um dos três níveis de saturação por bases, sendo esse volume de solo acondicionado em copos de plástico de $100 \mathrm{~cm}^{3}$.

Para a avaliação da nitrificação, adicionaram-se a cada copo $100 \mathrm{mg}$ de $\mathrm{N}$ por kg de solo, na forma de uréia ou de sulfato de amônio. Imediatamente após a adição do N, determinaram-se os teores iniciais de amônio e de nitrato bem como o pH em água das amostras de solo. Novamente, procedeu-se à incubação das amostras por 15 dias, em estufa com temperatura controlada $\left(26^{\circ} \mathrm{C}\right)$. A umidade foi mantida com $60 \%$ do volume total de poros de cada solo ocupado com água. Ao término desse período, foi realizada a determinação do $\mathrm{pH}$ em água, executando-se, a seguir, a extração e determinação do amônio remanescente e de nitrato, por meio do uso de $\mathrm{KCl} 1 \mathrm{~mol} \mathrm{~L}^{-1}$ na relação 1:10 (solo:extrator) e da técnica de destilação por arraste de vapores, respectivamente.

A quantidade de $\mathrm{N}$ nitrificado, nos dois experimentos, foi calculada em função do nitrato produzido durante os 15 dias de incubação, de acordo com a fórmula utilizada por Silva et al. (1994).

Os dados foram submetidos à analise de variância e à comparação entre médias feita pelo teste de Tukey, a 5\% de probabilidade.

\section{RESULTADOS E DISCUSSÃO}

\section{Nitrificação sob efeito de fontes e doses de $\mathbf{N}$}

Os teores de nitrato sob influência da adição de doses crescentes de sulfato de amônio ou uréia são apresentados na Fig. 1. A adição de doses crescentes de $\mathrm{N}$-uréia resultou em aumento na disponibilidade de nitrato nos cinco solos do sudoeste da Bahia. Quando o $\mathrm{N}$ foi aplicado na forma de sulfato de 
TABELA 2. Análise química de amostras da camada superficial $(0-20 \mathrm{~cm})$ de cinco solos do sul de Minas Gerais submetidos a doses crescentes de $\mathrm{CaCO}_{3}$, incubados por 30 dias.

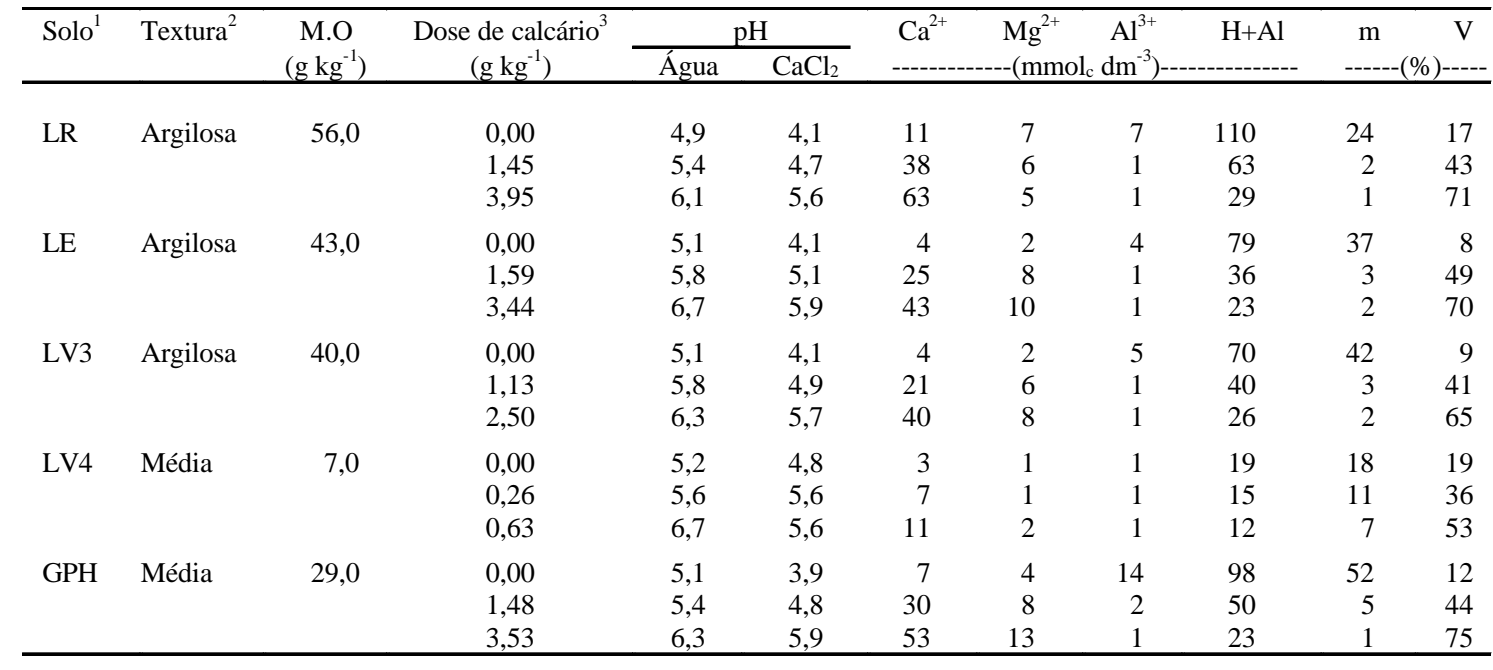

${ }^{1}$ LR: Latossolo Roxo; LE: Latossolo Vermelho-Escuro; LV3: Latossolo Vermelho-Amarelo; LV4: Latossolo Vermelho-Amarelo; GPH: Glei Pouco Húmico.

${ }^{2}$ Teor de argila: LR: $470 \mathrm{~g} \mathrm{~kg}^{-1}$; LE: $360 \mathrm{~g} \mathrm{~kg}^{-1}$; LV3: $440 \mathrm{~g} \mathrm{~kg}^{-1}$; LV4: $220 \mathrm{~g} \mathrm{~kg}^{-1}$; GPH: $120 \mathrm{~g} \mathrm{~kg}^{-1}$.

${ }^{3}$ Quantidade de calcário adicionada visando atingir os três graus de acidez dos solos testados.

amônio, o acréscimo nas doses de $\mathrm{N}$ somente elevou a intensidade de nitrificação nos solos LA e LV1 (Fig. 1). Independentemente da dose de $\mathrm{N}$ adicionada, os teores de nitrato no solo foram maiores para o amônio proveniente da uréia do que para o $\mathrm{N}$-sulfato de amônio. A maior intensidade de nitrificação, para as duas fontes de $\mathrm{N}$ utilizadas, foi observada no LA. Verifica-se, pela análise da Tabela 1, que esse solo foi o que apresentou o maior valor de $\mathrm{pH}$. Baseandose em resultados de estudos de nitrificação em solos brasileiros, Silva et al. (1994) sugerem ser o grau de acidez do solo o principal fator condicionante do processo de nitrificação. Segundo esses autores, as taxas de nitrificação caem rapidamente em valores de $\mathrm{pH}$ menores que 6,0, tornando-se bastante reduzidas em solo com pH abaixo de 5,0.

Um dos fatores que exercem forte influência sobre a nitrificação é a variação de $\mathrm{pH}$ do solo provocada pelas diferentes fontes de N. Segundo Sandanam et al. (1978) e Wickramasinghe et al. (1985), a maior nitrificação do $\mathrm{N}$-uréia, em relação a outras fontes de $\mathrm{N}$, é decorrente da elevação do $\mathrm{pH}$ nas proximidades do grânulo desse fertilizante, quando da sua hidrólise inicial, promovendo condições favoráveis à nitrificação, no solo adjacente ao grânu- lo. Esse aumento de pH, segundo esses autores, é temporário, porém suficiente para favorecer a nitrificação. Mudanças nos valores de $\mathrm{pH}$ do solo assumem importância, principalmente em condições ambientais limítrofes à atividade dos organismos nitrificadores. A presença de carbono na molécula de uréia, de acordo com Martikainen (1985), é outro fator que condiciona nitrificação mais rápida desse fertilizante nitrogenado. Um outro fato a ser considerado é aquele relacionado com uma maior disponibilidade de $\mathrm{P}$ e K, em função do aumento do $\mathrm{pH}$ do solo com a adição da uréia (Aarnio \& Martikainen, 1992), o que resulta em maiores teores de $\mathrm{N}$ amoniacal no solo, dada a maior mineralização da matéria orgânica (Martikainen, 1985). A presença de teores elevados de amônio assume importância, já que a atividade e os níveis populacionais dos organismos nitrificadores autotróficos mostram-se condicionados pela disponibilidade de substrato no solo (Haynes, 1986).

Segundo Melo (1987), a baixa eficiência da uréia aplicada em condições de campo, quando comparada a outras fontes de $\mathrm{N}$, pode ser devido, em parte, às maiores taxas de nitrificação do $\mathrm{N}$ desse fertilizante e, conseqüentemente, a uma maior lixiviação de nitrato. 


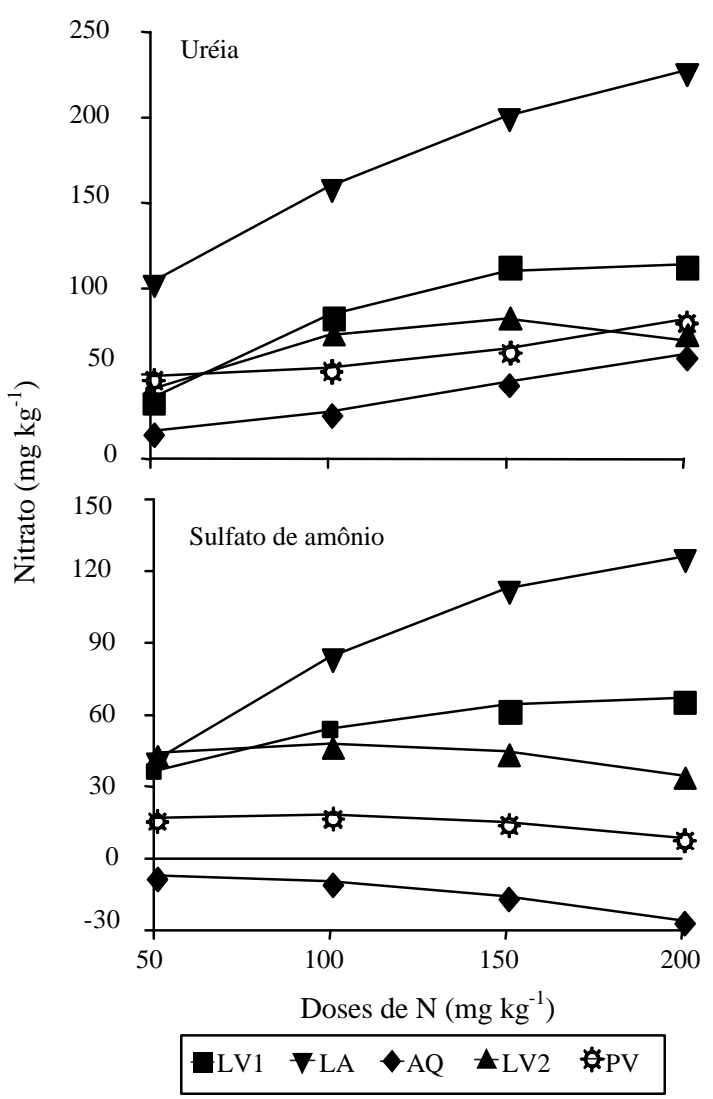

FIG. 1. Nitrato produzido, ao término dos 15 dias de incubação de amostras de solos $\left(\mathrm{LV}_{1}\right.$ : Latossolo Vermelho-Amarelo álico; LA: Latossolo Amarelo álico; AQ: Areia Quartzosa distrófica; $L V_{2}$ : Latossolo Vermelho-Amarelo eutrófico; PV: Podzólico Vermelho-Amarelo eutrófico) do sudoeste da Bahia, sob influência de fontes e doses de $\mathrm{N}$.

No solo AQ, não se observou nitrificação líquida do amônio proveniente do sulfato de amônio; para esse solo, ao término da incubação e para todas as doses de $\mathrm{N}$ testadas, foi notada uma redução nos teores de nitrato no solo, em relação aos teores quantificados no início do período de incubação (Fig. 1). Segundo Weber \& Gainey (1962), o sulfato de amônio provoca uma redução do $\mathrm{pH}$ do solo, que pode até inibir a nitrificação em solos ácidos. Low \& Piper (1970) observaram que o amônio proveniente da uréia nitrificou mais rapidamente do que o do sulfato de amônio e que em solo ácido, como o AQ, somente o amônio oriundo da uréia foi convertido a nitrato.
A baixa intensidade de nitrificação no solo $\mathrm{AQ}$ pode estar relacionada ao baixo teor de matéria orgânica e à reduzida disponibilidade de cátions trocáveis e nutrientes nesse solo (Tabela 1). Sandanam et al. (1978) sugerem a ocorrência de taxas reduzidas de formação de nitrato, quando da prevalência dessas condições no solo.

$\mathrm{Na}$ Tabela 3 são apresentados os coeficientes de correlação entre os teores de nitrato formado nos 15 dias de incubação e algumas propriedades químicas e físicas dos solos da Bahia. Entre as propriedades de solo consideradas, a saturação por bases foi a que apresentou a melhor correlação com o nitrato produzido, independentemente da fonte e dose de $\mathrm{N}$ aplicado. De modo similar, Freitas (1985) observou um aumento na produção de nitrato com o acréscimo no índice de saturação por bases.

\section{Efeito da calagem na nitrificação do $\mathbf{N}$-uréia e do N-sulfato de amônio}

Os dados relativos aos teores de amônio e nitrato, nos três níveis de acidez de solo testados, são apresentados na Tabela 4. No GPH, LR, LV3 e LE, na ausência de calagem, a intensidade da nitrificação foi reduzida, com predominância de amônio. No LV4, houve uma predominância de amônio em todos os níveis de $\mathrm{pH}$ testados, independentemente da fonte de $\mathrm{N}$ adicionada. Nesse solo, a correção da acidez, considerando a maior dose de calcário aplicada, pode ter resultado em imobilização do $\mathrm{N}$, presumidamente mais intensa com o uso da uréia.

A elevação da saturação por bases nos solos GPH, LR, LV3 e LE resultou em desaparecimento do amônio e, concomitantemente, conversão desse íon a nitrato (Tabela 4). A elevação de $\mathrm{pH}$ no LV3 pode ter propiciado, inclusive, mineralização do $\mathrm{N}$ orgânico, dadas as maiores quantidades de amônio e nitrato presentes nesses tratamentos, independentemente da adição do N como uréia ou sulfato de amônio (Tabela 4).

A análise dos dados de nitrato produzido em função da aplicação de carbonato de cálcio revelou que a nitrificação foi afetada pela correção da acidez do solo e pelas duas fontes de $\mathrm{N}$ utilizadas (Fig. 2).

No LR, LE, LV3 e GPH, a correção da acidez aumentou as quantidades de $\mathrm{N}$ nitrificado, independentemente da fonte de $\mathrm{N}$ adicionada, enquanto no LV4 os teores de nitrato produzido não se mos- 
TABELA 3. Coeficientes de correlação linear entre algumas propriedades do solo e os teores de nitrato em cinco solos do sudoeste da Bahia tratados com diferentes doses de uréia ou sulfato de amônio (SA) ${ }^{1}$.

\begin{tabular}{lcccccccc}
\hline Fonte de $\mathrm{N}$ & Dose de $\mathrm{N}$ & $\mathrm{MO}$ & $\mathrm{V}$ & $\mathrm{pH}$ em água & $\mathrm{CTC}$ a pH 7,0 & $\mathrm{Ca}^{2+}$ & Areia & Argila \\
\hline Uréia & 50 & $0,88^{*}$ & $0,84^{*}$ & 0,50 & $-0,26$ & $0,93^{*}$ & $-0,86^{*}$ & $0,81^{*}$ \\
& 100 & 0,49 & $0,83^{*}$ & $0,80^{*}$ & 0,33 & 0,52 & $-0,34$ & $-0,35$ \\
& 150 & 0,50 & $0,84^{*}$ & $0,83^{*}$ & 0,51 & 0,67 & 0,14 & 0,33 \\
& 200 & 0,36 & $0,81^{*}$ & $0,96^{*}$ & 0,30 & 0,49 & $-0,34$ & 0,06 \\
SA & 50 & $-0,33$ & $0,84^{*}$ & 0,68 & 0,66 & 0,77 & $-0,63$ & 0,53 \\
& 100 & 0,52 & $0,81^{*}$ & 0,66 & 0,55 & 0,69 & $-0,58$ & 0,39 \\
& 150 & 0,41 & $0,83^{*}$ & $0,94^{*}$ & 0,40 & 0,58 & $-0,45$ & 0,18 \\
& 200 & 0,37 & $0,80^{*}$ & $0,92^{*}$ & 0,37 & 0,55 & $-0,43$ & 0,15 \\
\hline
\end{tabular}

${ }^{1}$ MO: matéria orgânica: V: porcentagem de saturação por bases.

* Significativo a $5 \%$ de probabilidade.

TABELA 4. Teores iniciais e finais de amônio e de nitrato, valores de pH (água) no início e no final do período de incubação e variação de pH em função da incubação por 15 dias de amostras de cinco solos do sul de Minas Gerais com uréia ou sulfato de amônio (SA).

\begin{tabular}{|c|c|c|c|c|c|c|c|c|c|}
\hline \multirow[t]{2}{*}{ Solo $^{1}$} & \multirow{2}{*}{$\begin{array}{c}\text { Fonte } \\
\text { de } \mathrm{N}\end{array}$} & \multirow{2}{*}{$\begin{array}{l}\text { Dose de } \\
\text { calcário } \\
\left(\mathrm{g} \mathrm{kg}^{-1}\right)\end{array}$} & \multicolumn{2}{|c|}{$\mathrm{N}-\mathrm{NH}_{4}{ }^{+}$} & \multicolumn{2}{|c|}{ 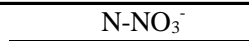 } & \multicolumn{2}{|c|}{$\mathrm{pH}$} & \multirow[t]{2}{*}{$\Delta \mathrm{pH}^{2}$} \\
\hline & & & Inicial & $\begin{array}{l}\text { Final } \\
-(\mathrm{mg} \mathrm{kg}\end{array}$ & $\begin{array}{l}\text { Inicial } \\
\text { de solo)-- }\end{array}$ & Final & Inicial & Final & \\
\hline \multirow[t]{6}{*}{ LR } & \multirow[t]{3}{*}{ Uréia } & 0,00 & 17 & 113 & 22 & 68 & 4,9 & 5,0 & $+0,1$ \\
\hline & & 1,59 & 17 & 43 & 17 & 122 & 5,4 & 4,7 & $-0,7$ \\
\hline & & 3,44 & 23 & 9 & 17 & 167 & 6,1 & 5,4 & $-0,7$ \\
\hline & \multirow[t]{3}{*}{ SA } & 0,00 & 107 & 130 & 20 & 59 & 4,9 & 4,7 & $-0,2$ \\
\hline & & 1,59 & 107 & 65 & 14 & 109 & 5,4 & 4,6 & $-0,8$ \\
\hline & & 3,44 & 108 & 17 & 16 & 148 & 6,1 & 5,2 & $-0,9$ \\
\hline \multirow[t]{6}{*}{$\mathrm{LE}$} & \multirow{3}{*}{ Uréia } & 0,00 & 18 & 135 & 7 & 8 & 5,1 & 6,4 & $+1,3$ \\
\hline & & 1,48 & 17 & 106 & 7 & 43 & 5,8 & 6,1 & $+0,3$ \\
\hline & & 3,53 & 20 & 30 & 10 & 115 & 6,7 & 6,1 & $-0,6$ \\
\hline & \multirow[t]{3}{*}{ SA } & 0,00 & 113 & 136 & 7 & 9 & 5,1 & 5,3 & $+0,2$ \\
\hline & & 1,48 & 110 & 128 & 7 & 19 & 5,8 & 5,8 & 0,0 \\
\hline & & 3,53 & 113 & 71 & 7 & 78 & 6,7 & 6,1 & $-0,6$ \\
\hline \multirow[t]{6}{*}{ LV3 } & \multirow[t]{3}{*}{ Uréia } & 0,00 & 17 & 117 & 7 & 13 & 5,1 & 5,8 & $+0,7$ \\
\hline & & 1,13 & 18 & 118 & 7 & 29 & 5,8 & 6,0 & $+0,2$ \\
\hline & & 2,50 & 27 & 107 & 7 & 41 & 6,3 & 6,5 & $+0,2$ \\
\hline & \multirow[t]{3}{*}{ SA } & 0,00 & 110 & 115 & 7 & 14 & 5,1 & 5,0 & $-0,1$ \\
\hline & & 1,13 & 115 & 115 & 7 & 26 & 5,8 & 5,0 & $-0,1$ \\
\hline & & 2,50 & 117 & 125 & 7 & 26 & 6,3 & 6,2 & $-0,1$ \\
\hline \multirow[t]{6}{*}{ LV4 } & \multirow{3}{*}{ Uréia } & 0,00 & 10 & 105 & 7 & 10 & 5,2 & 7,4 & $+2,2$ \\
\hline & & 0,26 & 10 & 101 & 7 & 11 & 5,6 & 8,0 & $+2,4$ \\
\hline & & 0,63 & 10 & 80 & 7 & 11 & 6,7 & 8,0 & $+1,3$ \\
\hline & \multirow[t]{3}{*}{ SA } & 0,00 & 110 & 106 & 7 & 9 & 5,2 & 5,9 & $+0,7$ \\
\hline & & 0,26 & 108 & 110 & 7 & 9 & 5,6 & 6,5 & $+0,9$ \\
\hline & & 0,63 & 108 & 97 & 7 & 8 & 6,7 & 7,1 & $+0,4$ \\
\hline \multirow[t]{6}{*}{ GPH } & \multirow[t]{3}{*}{ Uréia } & 0.00 & 23 & 158 & 7 & 11 & 5,1 & 6,0 & $+0,9$ \\
\hline & & 1.45 & 20 & 34 & 20 & 133 & 5,4 & 4,6 & $-0,8$ \\
\hline & & 3.95 & 17 & 9 & 22 & 156 & 6,3 & 5,6 & $-0,7$ \\
\hline & \multirow[t]{3}{*}{ SA } & 0.00 & 123 & 167 & 7 & 13 & 5,1 & 4,8 & $-0,3$ \\
\hline & & 1,45 & 120 & 75 & 20 & 94 & 5,4 & 4,6 & $-0,8$ \\
\hline & & 3,95 & 111 & 9 & 23 & 143 & 6,3 & 5,4 & $-0,7$ \\
\hline
\end{tabular}

${ }^{1}$ LR: Latossolo Roxo; LE: Latossolo Vermelho-Escuro; LV3: Latossolo Vermelho-Amarelo; LV4: Latossolo Vermelho-Amarelo; GPH: Glei Pouco Húmico.

${ }^{2} \Delta \mathrm{pH}=\mathrm{pH}$ (início do período de incubação) - pH (término do período de incubação). 

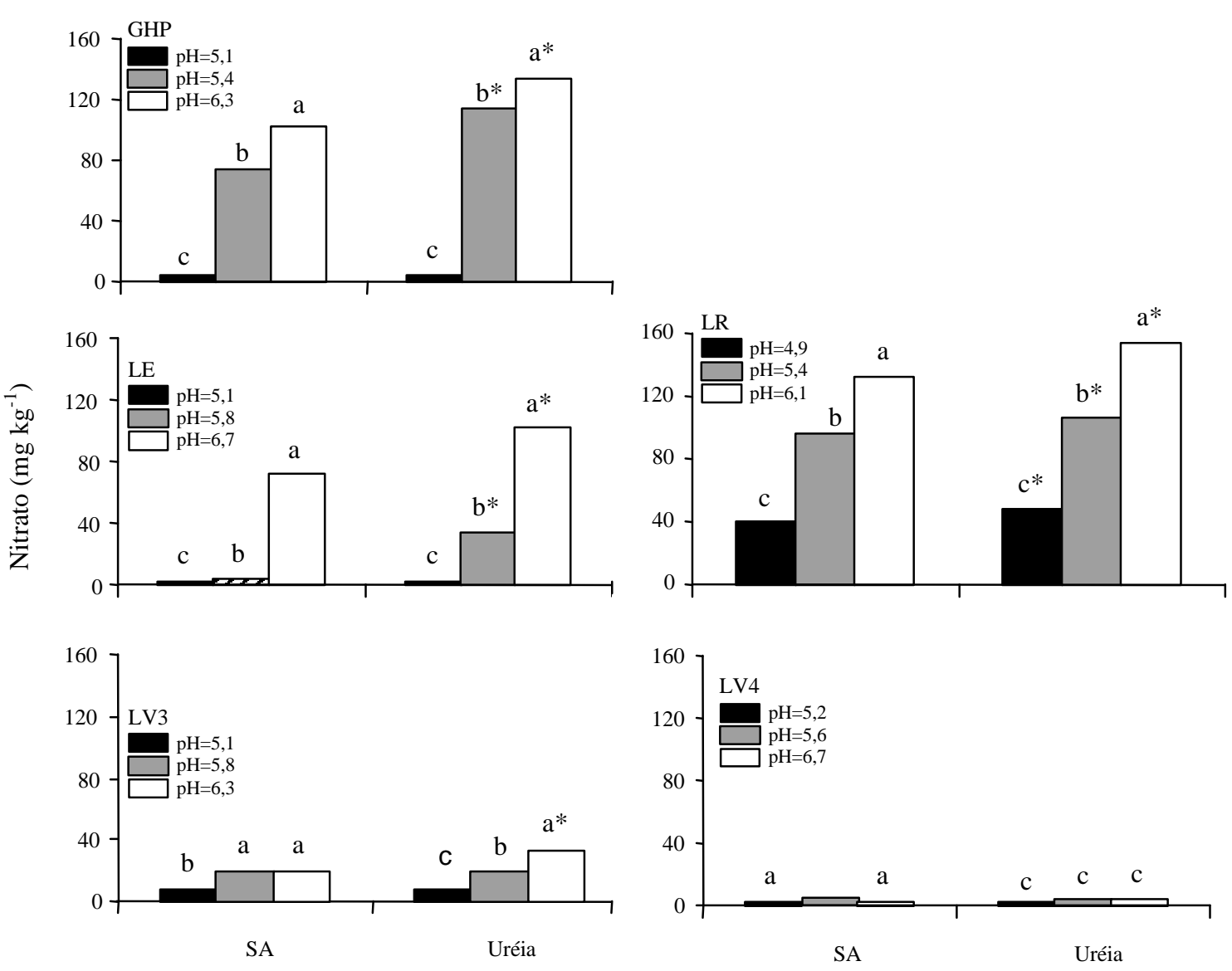

Fontes de N

FIG. 2. Efeito da acidez do solo e da adição de $\mathrm{N}$, na forma de uréia ou sulfato de amônio (SA), sobre a produção de nitrato em cinco solos $\left(\mathrm{LV}_{3}\right.$ : Latossolo Vermelho-Amarelo; $\mathrm{LV}_{4}$ : Latossolo VermelhoAmarelo; LE: Latossolo Vermelho-Escuro; LR: Latossolo Roxo; GHP: Glei Pouco Húmico) do sul de Minas Gerais. Médias com letras iguais nas barras de cada solo e para a mesma fonte de nitrogênio, não diferem entre si pelo teste de Tukey a $5 \%$ de probabilidade; os asteríscos indicam diferença significativa entre fontes de $\mathrm{N}$, dentro de cada nível de $\mathrm{pH}$, pelo teste de Tukey a $5 \%$ de probabilidade.

traram dependentes dos níveis de saturação por bases, tanto com o uso do sulfato de amônio quanto da uréia (Fig. 2). No LR, os teores de nitrato produzido foram significativamente maiores para o $\mathrm{N}$ oriundo da uréia, em relação àquele suprido pelo sulfato de amônio. Entre os cinco solos estudados, o LR caracterizou-se por ser o único a apresentar, nos três níveis de acidez do solo testados, uma maior nitrificação do N-uréia, em relação ao N-sulfato de amônio. Possivelmente, a maior intensidade da nitrificação nesse solo, obtida com a adição do $\mathrm{N}$ na forma de uréia e em condições de elevada acidez, deve estar relacionada à alta atividade da urease (Santos et al., 1991). As condições específicas de ambiente verificadas em sistemas sob vegetação de floresta, como no caso do LR, propiciam proteção à urease (Zantua \& Bremner, 1975), favorecendo a hidrólise da uréia.

No solo LV4 foram reduzidos os teores de nitrato formado, mesmo com a adição do $\mathrm{N}$ como uréia (Fig. 2). A quantidade máxima de nitrato produzida 
nesse solo situou-se em torno de $4 \mathrm{mg} \mathrm{kg}^{-1}$ de solo. Contudo, não foi verificado impedimento à hidrólise da uréia nesse solo, dado que, no geral, quase todo o $\mathrm{N}$ adicionado nessa forma foi recuperado ao final dos 15 dias de incubação na forma de amônio (Tabela 4). As baixas quantidades de $\mathrm{N}$ nitrificado no LV4, possivelmente, se deveu aos níveis reduzidos da matéria orgânica, argila, $\mathrm{Ca}^{2+} \mathrm{e} \mathrm{Mg}^{2+}$ presentes no mesmo. Nessas condições, é comum uma redução na população de microrganismos nitrificadores e diminuição na intensidade da nitrificação (Sandanam et al., 1978; Yadvinder-Singh \& Beauchamp, 1986).

Para os outros solos (LE, LV3 e GPH), só foi verificada nitrificação mais intensa da uréia nos valores de $\mathrm{V}$ mais elevados, quando o $\mathrm{pH}$ dos solos estava próximo da neutralidade (Fig. 2). Os dados obtidos para esses solos não estão de acordo com as observações de Sandanam et al. (1978), visto que no estudo desses autores só foi verificada uma maior nitrificação do $\mathrm{N}$ oriundo da uréia, em relação ao $\mathrm{N}$ adicionado pelo sulfato de amônio, em condições de elevada acidez.

O comportamento similar dos adubos uréia e sulfato de amônio, em condições de baixo $\mathrm{pH}$, nos solos GPH, LE e LV3, pode estar relacionado ao fato de a elevação de $\mathrm{pH}$ provocada pela hidrólise da uréia, nessas condições, não ter sido suficiente para resultar em uma maior disponibilidade de amônio oriundo da mineralização, dados os baixos teores de matéria orgânica presentes nesses solos. Também, esses acréscimos de $\mathrm{pH}$ podem não ter sido suficientemente elevados, a ponto de estimularem uma maior atividade dos organismos nitrificadores. Estes resultados não concordam com aqueles apresentados por Martikainen (1985) e Aarnio \& Martikainen (1992), os quais observaram que a adição da uréia a solos ácidos resultou numa maior intensidade do processo de nitrificação.

Em resumo, verificou-se comportamento diferenciado entre as duas fontes de $\mathrm{N}$ sobre a nitrificação, na medida em que o $\mathrm{N}$ adicionado como uréia foi nitrificado mais intensamente, para níveis similares de $\mathrm{pH}$ do solo, do que aquele oriundo do sulfato de amônio. Esse comportamento só não foi observado no solo LV2, cujos teores de nitrato produzido não se mostraram influenciados pela acidez do solo, tampouco pelas fontes de $\mathrm{N}$ utilizadas. No nível mais elevado de acidez, o LR, entre os cinco solos estudados, foi o único a apresentar uma maior intensidade nas quantidades de $\mathrm{N}$ nitrificado oriundo da uréia.

\section{Hidrólise da uréia em solos do sudoeste da Bahia}

Os teores de uréia remanescente, após os 15 dias de incubação de amostras de solos do sudoeste da Bahia, encontram-se na Fig. 3. Os resultados apresentados mostram comportamento altamente diferenciado entre solos em relação à hidrólise da uréia com o aumento de sua concentração. Quando se adicionou, por exemplo, $200 \mathrm{mg} \mathrm{kg}^{-1} \mathrm{de} \mathrm{N}$-uréia, a quantidade de $\mathrm{N}$-uréia remanescente no solo com o menor teor de matéria orgânica foi cerca de 4,5 vezes maior do que aquela observada no solo com maior teor de carbono. Nas outras doses de N-uréia adicionadas, esse intervalo foi menor, sendo observada uma hidrólise de mais de $80 \%$ do $\mathrm{N}$-amídico adicionado, na dose de $50 \mathrm{mg} \mathrm{kg}^{-1}$ de $\mathrm{N}$-uréia, em todos os solos. A Areia Quartzosa foi o solo que apresentou a menor velocidade de hidrólise da uréia, em todas as doses de $\mathrm{N}$-uréia, principalmente naquelas acima de $50 \mathrm{mg} \mathrm{kg}^{-1}$ de solo. Os teores de uréia remanescente

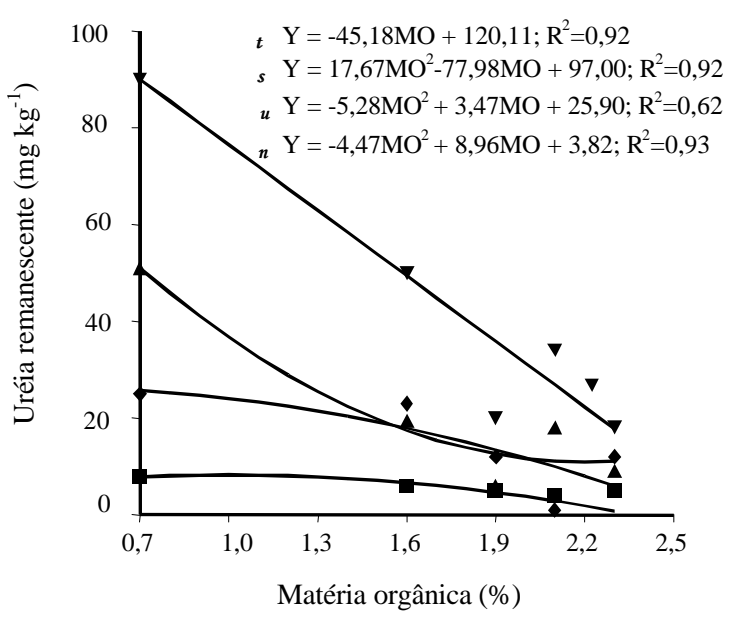

FIG. 3. Teores de uréia remanescente de cinco amostras de solos do sudoeste da Bahia, com diferentes teores de matéria orgânica, após 15 dias de incubação com doses de uréia $(n, u, s, t$ respectivamente, 50, 100, 150 e $200 \mathrm{mg} \mathrm{kg}^{-1}$ de solo). 
se mostraram altamente dependentes dos estoques de matéria orgânica, sendo notada maior conversão do $\mathrm{N}$-amídico a amônio nos solos mais ricos em carbono.

A taxa de hidrólise da uréia é influenciada por vários fatores, entre os quais o tipo de solo, a concentração de substrato, o teor de matéria orgânica, o estoque de $\mathrm{N}$ total, a textura e o pH do solo (Pancholy \& Rice, 1973; Zantua \& Bremner, 1975; Santos et al., 1991). De fato, o nível de atividade da urease é determinado pela habilidade dos colóides em efetuar a proteção dessa enzima, muito embora, por se originar de metabólitos de plantas e de microrganismos, a urease seja dependente também da quantidade e tipo de resíduos vegetais e da atividade e diversidade microbiana. A intensidade de processos microbianos no solo se mostra bastante dependente do teor de matéria orgânica, sendo razoável a constatação nesse estudo de maior hidrólise de uréia nos solos mais ricos em carbono, fato esse não verificado por Santos et al. (1991), quando da avaliação de parâmetros cinéticos da hidrólise da uréia em solos do sul de Minas Gerais.

\section{Acidez do solo sob efeito da intensidade de nitri- ficação}

A análise do $\mathrm{pH}$ de amostras de solos do sudoeste da Bahia, efetuada após quinze dias de incubação, mostrou que, para a maioria dos solos, houve um decréscimo no $\mathrm{pH}$ com o aumento da dose de $\mathrm{N}$ (Fig. 4). Para os solos LA, LV1, PV e AQ, a adição de $\mathrm{N}$-uréia acidificou menos os solos do que o N-sulfato de amônio. Na Tabela 4 são apresentadas as variações de pH do solo resultantes da aplicação de uréia e sulfato de amônio em amostras de solos do sul de Minas Gerais, sendo essas variações calculadas a partir da medição de $\mathrm{pH}$ em água, no início e ao término dos 15 dias de incubação. No LV4, independentemente da fonte de $\mathrm{N}$ utilizada, houve uma elevação nos valores de $\mathrm{pH}$ do solo, refletidos pelos valores positivos de variação de $\mathrm{pH}$. Nesse solo, para os três níveis de acidez testados, os maiores aumentos de $\mathrm{pH}$ foram verificados com a adição da uréia. Os maiores acréscimos de $\mathrm{pH}$ detectados no LV4 podem ser explicados pela hidrólise dessa forma nitrogenada, nesse solo com baixo poder tampão,

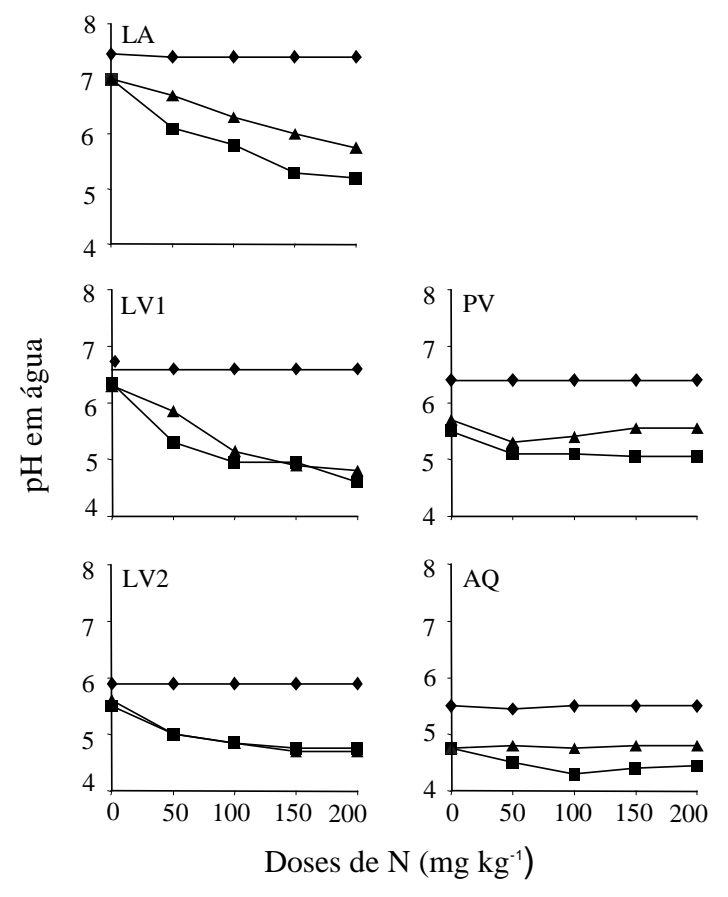

FIG. 4. Valores de pH inicial ( $\bullet$ e após a incubação de cinco amostras de solo (LA: Latossolo Amarelo álico ; $\mathbf{L V}_{1}$ : Latossolo Vermelho-Amarelo álico; PV Podzólico Vermelho-Amarelo eutrófico; $\mathbf{L V}_{2}$ : Latossolo Vermelho-Amarelo eutrófico; AQ: Areia Quartzosa distrófica) do sudoeste da Bahia, por um periódo de 15 dias, com uréia ( $₫)$ ou sulfato de amônio (•).

associada à baixa intensidade de nitrificação. As variações de $\mathrm{pH}$ ocorreram de acordo com o tipo de solo estudado e a dose de calcário aplicada (Tabela 4). Quando se verificaram quedas nos valores de $\mathrm{pH}$ do solo, essas foram iguais ou de menor intensidade nos tratamentos em que se adicionou uréia, em relação àqueles em que se utilizou o sulfato de amônio. Esses resultados estão de acordo com os de outros estudos que descrevem variações de $\mathrm{pH}$ com a adição de fertilizantes nitrogenados (Martikainen, 1985; Alfaia, 1997).

Segundo Adams \& Martin (1984), a acidez depende dos efeitos integrados das propriedades do solo, do sistema de cultivo, do modo de aplicação, da dose e forma do $\mathrm{N}$ adicionado ao solo. Nas condições específicas deste estudo, esses fatores determinaram 
diferentes intensidades de nitrificação e de velocidade de hidrólise da uréia. Desse modo, os níveis de $\mathrm{H}^{+}$ medidos nos diferentes tratamentos estudados refletem o balanço, em termos de acidificação, das taxas desses dois processos nos diferentes solos investigados.

\section{CONCLUSÕES}

1. A nitrificação do N-uréia é mais intensa do que a do N-sulfato de amônio.

2. No solos LA, LV1, AQePV, a adição de até $200 \mathrm{mg}$ de N-uréia por kg de solo resulta em aumentos progressivos nos teores de nitrato no solo.

3. A hidrólise da uréia é afetada pelos teores de matéria orgânica, sendo observada maior conversão do $\mathrm{N}$-amídico a amônio nos solos mais ricos em carbono.

4. A calagem afeta a nitrificação, sendo verificada uma produção média de $11,6 \mathrm{mg} \mathrm{kg}^{-1}$ de nitrato nos solos onde não se adiciona calcário, e de $62,7 \mathrm{mg} \mathrm{kg}^{-1}$ onde a acidez é corrigida.

\section{REFERÊNCIAS}

AARNIO, T.; MARTIKAINEN, P.J. Nitrification in forest soil after refertilization with urea and dicyandiamide. Soil Biology \& Biochemistry, Oxford, v.24, n.10, p.951-954,1992.

ADAMS, F; MARTIN, J.B. Liming effects on nitrogen: use and efficiency. In: HAUCK, R.D. (Ed.). Nitrogen in crop production. Madison : American Society of Agronomy, 1984. p.417-426.

ALEXANDER, M. Nitrification. In: BARTHOLOMEW, W.V.; CLARK, F.E. (Ed.). Soil nitrogen. Madison : American Society of Agronomy, 1965. p.307-343.

ALFAIA, S.S. Destino de adubos nitrogenados marcados com ${ }^{15} \mathrm{~N}$ em amostras de dois solos da Amazônia Central. Revista Brasileira de Ciência do Solo, Viçosa, v.21, p.379-385,1997.

ARORA, Y.; MULONGOY, K.; JUO, A.S.R. Nitrification and mineralization potentials in a limed Ultisol in the humid tropics. Plant and Soil, Dordrecht, v.92, p.153-157, 1986.
BREMNER, J.M. Nitrogen-urea. In: PAGE, A.L. (Ed.). Methods of soil analysis: chemical and microbiological properties. 2.ed. Madison : American Society of Agronomy/Soil Science Society of America, 1982. p.699-709.

BREMNER, J.M.; MULVANEY, C.S. Nitrogen-total. In: PAGE, A.L. (Ed.). Methods of soil analysis: chemical and microbiological properties. 2.ed. Madison : American Society of Agronomy/Soil Science Society of America, 1982. p.595-624.

CAMARGO, O.A.; MONIZ, A.C.; JORGE, J.A.; VALADARES, J.M.A.S. Métodos de análise química, mineralógica e física de solos do Instituto Agronômico de Campinas. Campinas : IAC, 1986. $94 \mathrm{p}$.

EMBRAPA. Serviço Nacional de Levantamento e Conservação de Solos (Rio de Janeiro, RJ). Manual de métodos de análises do solo. Rio de Janeiro, 1979. não paginado.

FREITAS, S.S. Mineralização e imobilização do nitrogênio em solo suplementado com torta de filtro de usina de açúcar de cana e carbonato de cálcio. Piracicaba : ESALQ, 1985. 65p. Dissertação de Mestrado.

HAYATSU, M.; KOSUGE, N. Effects of urea fertilization and liming on nitrification in Cerrados soils (Brazil). Soil Science and Plant Nutrition, Tokyo, v.39, p.367-371, 1993.

HAYNES, R.J. Nitrification. In: (Ed.). Mineral nitrogen in the plant-soil system. Madison : Academic, 1986. p.127-164.

KEENEY, D.R.; NELSON, D.W. Nitrogen inorganic forms. In: PAGE, A.L. (Ed.). Methods of soil analysis: chemical and microbiological properties. 2.ed. Madison : American Society of Agronomy/Soil Science Society of America, 1982. p.643-698.

KREUTZER, K. Effects of forest liming on soil processes. Plant and Soil, Dordrecht, v.168/169, p.447470, 1995.

LOW, A.J.; PIPER, F.J. The ammonification and nitrification in soil of urea with and without biuret. Journal of Agricultural Science, Cambridge, Grã-Bretanha, v.75, p.301-309, 1970.

MALHI, S.S.; McGILL, W.B. Nitrification in three Alberta soils: effect of temperature, moisture and substrate concentration. Soil Biology \& Biochemistry, Oxford, v.14, p.393-399, 1982. 
MARTIKAINEN, P.J. Nitrification in forest soil of different $\mathrm{pH}$ as affected by urea, ammonium sulphate and potassium sulphate. Soil Biology \& Biochemistry, Oxford, v.17, p.363-367, 1985.

MELO, F.A.F. Uréia fertilizante. Campinas : Fundação Cargill, 1987. 192p.

MELO, F.A.F.; POSSÍDIO, E.L.; ARAÚJO, J.P.; ABRAMOFE, L.; COSTA, O.A.; KIEHL, J.C. Efeito da adição de uréia e do sulfato de amônio sobre a nitrificação em solo ácido. In: REUNIÃO BRASILEIRA DE FERTILIDADE DO SOLO, 14., Cuiabá, 1980. Anais. Campinas : Sociedade Brasileira de Ciência do Solo, 1980. p.77-81.

PANCHOLY, S.K.; RICE, E.L. Soil enzyme in relation to old field succession: amylase, cellulase, invertase, dehydrogenase and urease. Soil Science Society of America. Journal, Madison, v.7, p.47-50, 1973.

RAIJ, B. van. Fertilidade do solo e adubação. São Paulo : Agronômica Ceres/Potafos, 1991. 343p.

RAIJ, B. van; QUAGGIO, J.A. Métodos de análise de solo para fins de fertilidade. Campinas : Instituto Agronômico de Campinas, 1983. 31p. (Boletim Técnico, 81).

SANDANAM, S.; KRISHNAPILLAI, S.; SABARATNAM, J. Nitrification of ammonium sulphate and urea in an acid red yellow podzolic tea soil in Sri Lanka in relation to soil fertility. Plant and Soil, Dordrecht, v.49, p.9-22, 1978.
SANTOS, A.R.; VALE, F.R.; SANTOS, J.A.G. Avaliação de parâmetros cinéticos da hidrólise da uréia em solos do sul de Minas Gerais. Revista Brasileira de Ciência do Solo, Campinas, v.15, p.309-313, 1991.

SILVA, C.A.; VALE, F.R.; GUILHERME, L.R.G. Nitrificação em latossolos da região sul de Minas Gerais: efeito da acidez do solo. Ciência e Prática, Lavras, v.18, p.388-394,1994.

VALE, F.R.; GUAZELLI, E.M.F.; FURTINI NETO, A.E.; FERNANDES, L.A. Cultivo do feijoeiro em solução nutritiva sob proporções variáveis de amônio e nitrato. Revista Brasileira de Ciência do Solo, Campinas, v.22, p.35-42, 1998.

WEBER, D.F.; GAINEY, P.L. Relative sensitivity of nitrifying organisms to hydrogen ions in soils and solutions. Soil Science, Baltimore, v.94, p.138-148, 1962.

WICKRAMASINGHE，K.N.; RODGERS， G.A.; JENKINSON, D.S. Transformations of nitrogen fertilizers in soil. Soil Biology \& Biochemistry, Oxford, v.17, n.5, p.625-630, 1985.

YADVINDER-SINGH; BEAUCHAMP, E.G. Nitrogen mineralization and nitrifier activity in limed and urea treated soils. Communications in Soil Science and Plant Analysis, New York, v.17, n.12, p.13691381, 1986.

ZANTUA, M.I.; BREMNER, J.M. Preservation of soil samples for assay of urease activity. Soil Biology \& Biochemistry, Oxford, v.7, p.297-299, 1975. 